\title{
Community Work Project in Gazankulu: A Community-Based Training Experience
}

\author{
Melissa A. Bortz, Barbara Schoub \\ Department of Speech Pathology and Audiology, \\ University of the Witwatersrand, Johannesburg, South Africa \\ Judy McKenzie \\ Rehabilitation Unit, Tintswalo Hospital, Acornhoek, Gazankulu
}

\begin{abstract}
Speech Pathology and Audiology students at the University of the Witwatersrand participated in a field trip to learn about ru ral community work. In collaboration with rehabilitation workers at Tintswalo Hospital, Gazankulu, projects in pre-school language stimulation, aphasia assessment and intervention, and hearing screening were undertaken. Projects adhered to community work principles. These were successful in terms of both providing a service to the community and teaching students principles and practice of community work.
\end{abstract}

\section{OPSOMMING}

Spraakheelkunde en audiologie studente van die Universiteit van die Witwatersrand het aan 'n plattelands gemeenskapswerkprojek, as deel van hul onderrig, deelgeneem. Projekte in voorskoolse taalstimulasie, afasie-evaluasie en terapie en gehoorsifting, is in samewerking met die rehabilitasie-werkers van Tintswalo Hospitaal in Gazankulu onderneem. Die projekte het aan die beginsels van gemeenskapswerk voldoen. Hierdie projekte was suksesvol, beide in terme van dienslewering aan die gemeenskap en die opleiding van die studente in die beginsels en praktyk van gemeenskapwerk.

The discipline of epidemiology has been concerned with prevention of disease and is used to study relationships between people, their diseases and the agents that cause, prevent or cure their disease in the environment (Kibbel \& Wagstaff, 1991). When considering prevention of communication disorders from an epidemiological perspective, prevention usually occurs at three levels, primary, secondary and tertiary (Gerber, 1990). Primary prevention is aimed at the promotion of good health by reducing the incidence of disease or where the occurrence of a communicative disorder can be eliminated, for example, by mass public education; secondary prevention is the early detection and treatment of a communication problem and aims at reducing the prevalence of disease while tertiary prevention is rehabilitation where traditionally speech and hearing therapists have focused their attention (Butler, 1989; Gerber, 1990). Gerber (1990) does not deny that rehabilitation is necessary but has suggested that it would be positive "for humankind were we to have more primary and secondary prevention" (Gerber, 1990, p. xiv).

Primary prevention can be instituted by means of primary health care which the WHO-UNICEF meeting (1978) cited by Walt and Vaughan (1981, p. 1) has declared is

essential health care based on practical, scientifically sound and socially acceptable methods and technology, made universally accessible to individuals and families in the community through their full participation and at a cost that the community and country can afford to maintain at every stage of their development in the spirit of self-reliance and self determination.
One of the methods currently used to institute primary health care is community work, which de Vries (1984) believes is an effective means of promoting health through collective action to prevent disease. According to the Calouste Gulbenkian Foundation (1973) community work is essentially concerned with affecting the course of social change through analysing social situations and forming relationships with different groups to bring about change (1973).

Currently South Africa's population is estimated at approximately 35 million people. In 1978 Penn reported that although few incidence studies had been conducted in South Africa those performed, indicate that $8-10 \%$ of the population have a communication difficulty. Based upon these figures there could, currently, be as many as 3,5 million people with disorders of communication. Drew (1982, p. 1) has contended that "there are vast sections of the population who do not receive even the most basic speech therapy and audiological care" and according to Aron (1984), if one takes into account the number of speech, language and hearing therapists working, it appears that only approximately 138000 patients are receiving any form of treatment. A possible reason for this is that speech and hearing therapy students are "not only drawn from the privileged sections of the population, but tend to operate within these sections" (Drew, 1982, p. 1). In addition, Adler (1979) has asserted that speech and hearing therapists tend to treat patients "in rather centralised geographic locations" (p. xiii).

The Department of Speech Pathology and Audiology at the University of the Witwatersrand (Wits) has been attempting to 
deal comprehensively with the lack of speech and hearing personnel by the training of different tiers of workers who would provide services to broader spectrums of the community than currently occurs. (See model presented in Figure 1).

In addition, Wits is striving to make the training of the four year degree in speech therapy and audiology more appropriate for the South African population. One of the methods that has been utilised, is community therapy so that "students can be made aware of the needs of different sectors of the community" (Segal, 1982, p. 17). Therefore, at present, community work principles are incorporated into all aspects of student training. One of the methods used to achieve this, is the use of regular field trips into the community to carry out speech, language and hearing based projects.

The field trip that is to be described took place in the Mhala district of Gazankulu, a rural community with a population of approximately 200000 people. Most of the inhabitants live in villages of which there are 75 , although there are also four towns. Villagers have limited access to farming land and water needed for drinking and irrigation purposes. There is a high rate of unemployment and poverty, with people who are employed, being paid at the rate of between $R 2,00$ and $R 5,00$ per day (Wits Rural Facility, 1991). Because of limited employment opportunities, many people become migrant labourers, causing a breakdown in traditional family structure and culture. In addition, a large number of Mozambican refugees have recently settled in this area, causing further strain on existing resources.

Medical facilities of this region consist of a 266 bed hospital (Tintswalo), two health care centres, 10 permanent clinics and one mobile clinic. At Tintswalo two occupational therapists (OTs), a social worker, a part-time speech and hearing therapist, two community workers in speech and hearing, three assistants in occupational therapy, and two in physiotherapy, work together as a rehabilitation team.
In response to the need for making rehabilitation more accessible and affordable, the Tintswalo rehabilitation team, in conjunction with the Occupational Therapy Department of the University of the Witwatersrand, is engaged in the process of training community rehabilitation workers at Tintswalo Hospital (Unit for the Development of Rehabilitation Strategies, 1992). The community rehabilitation workers are representatives selected from different villages in the Mhala district and trained in basic principles of speech therapy, physiotherapy and occupational therapy and their application.

The field trip was a joint project planned by the Tintswalo rehabilitation team and the Department of Speech Pathology at Wits, and integrated with Tintswalo's community rehabilitation worker training programme. The project was based upon methods used in speech and hearing such as hearing screening and community work principles, which "refer to various intervention approaches by a professional practitioner to help a community engage in conscious collective action in order to respond to social problems" (Mitchell, 1987, p. 109).

According to the Calouste Gulbenkian Foundation (1973, p. 21), community work comprises certain characteristic steps which the field trip was designed to incorporate:

1) study the situation

2) establish rapport and a network of communication links with the community

3) gather information, analyse the relationship between community wants and needs and identify alternative ways of meeting needs

4) create some basis of organisation and of resources, work on the programme, modifying procedures and objectives as experience grows

5) review and develop progress to determine the next steps.

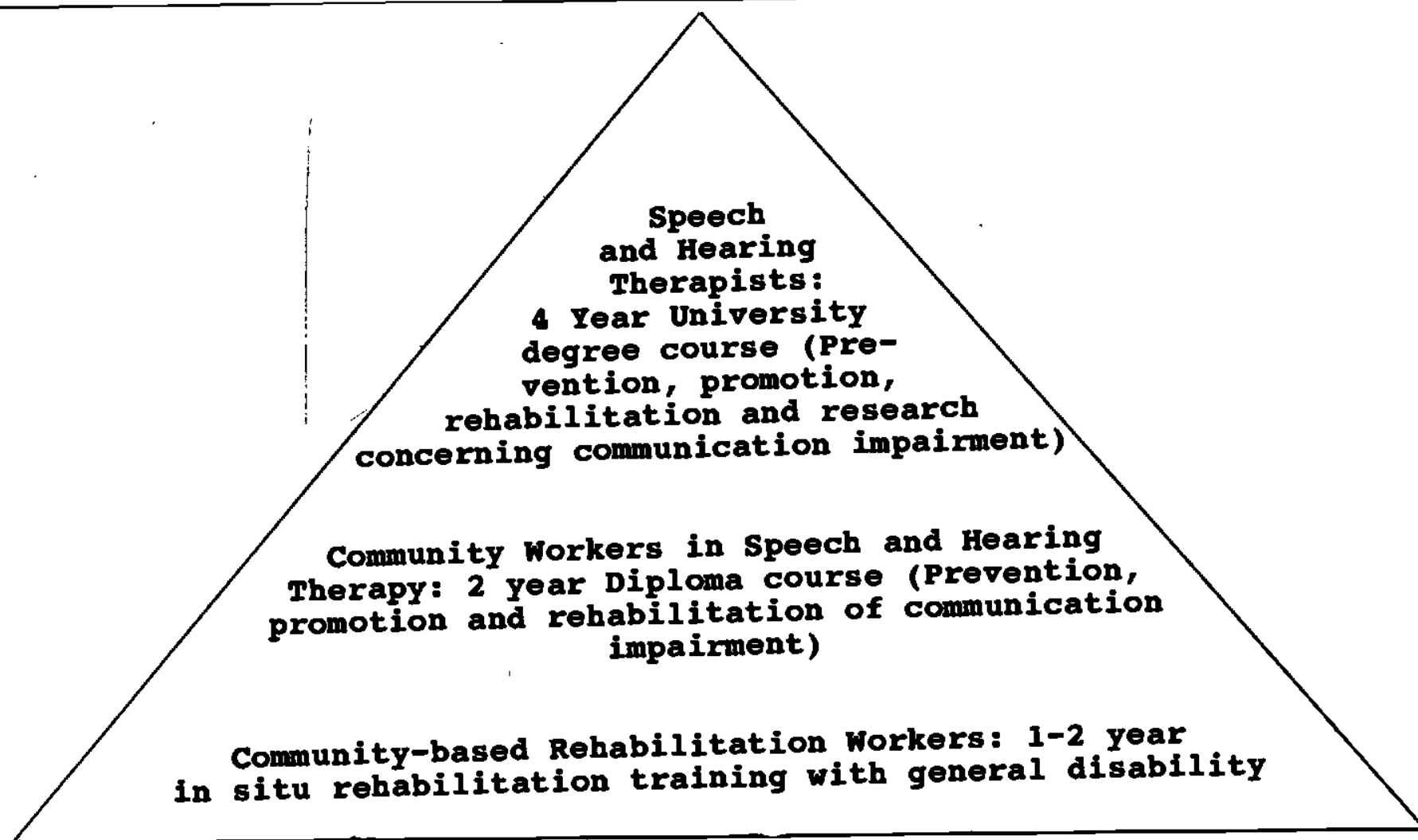

Figure 1: Proposed model for personnel involved in treatment of communication problems. (Department of Speech Pathology and Audiology, University of the Witwatersrand). 
Mitchell (1987) has reported that the final stage of a community work project is evaluation which is the process by which the participants in a project assess the extent to which the project has met its objectives. Cooper and Heenan (1980) believe that evaluation should be carried out on an ongoing basis while the project is in progress, and a concluding evalua. tion session should be held in which the overall project is evaluated in terms of the extent to which it has met the stated expectations and goals.

\section{THE FIELD TRIP}

\section{Aim}

The purpose of the field trip, for the Wits students was to learn community work principles and experience conditions in rural areas. The aim of the field trip for the Tintswalo rehabilitation team was to engage in speech and language projects they had identified as necessary but had not carried out due to lack of adequate personpower. For the community the purpose of the field trip was to receive language and hearing services.

\section{Participants}

Three staff members and 14 students from Wits participated in the three selected projects for the field trip, together with members of the Tintswalo rehabilitation team and community rehabilitation workers. All participants in the field trip were divided into the three selected projects discussed below.

\section{Planning}

Feasibility and organizational details were discussed at a planning workshop held in Gazankulu with members of staff from the Tintswalo rehabilitation team, from the community rehabilitation worker training programme and from the Department of Speech Pathology and Audiology, Wits. This took place a month before the field trip. Three projects were selected to be undertaken by participants in the field trip. These were new projects selected for the field trip according to needs previously identified in the community by the Tintswalo rehabilitation team. The selected field trip projects were:

1. A language stimulation project consisting of Wits students and staff and a community worker in speech and hearing which aimed to educate childminders at local creches about the development of language and the importance of language stimulation and play.

2. A stroke rehabilitation project whose objectives were for Wits staff and students to train student community rehabilitation workers about speech and language problems associated with stroke. A further objective was to devise relevant and appropriate assessment and management procedures for aphasic patients in this setting.

3. A hearing screening and education project aimed at identifying hear ing problems by conducting hearing screening at three schools. In addition, this group would be used to provide information about hearing loss and management to teachers and members of a self help group that had deaf members.

The month between the planning workshop and the field trip was used to organise such practical details as transport from Wits to Tintswalo, and in Gazankulu; and accommodation for Wits students and other participants in the language stimulation group.

To the writers' knowledge this is one of the first occasions that a project of this nature, combining the fields of community work and speech and hearing has taken place, and there are no recognised evaluation procedures or standardised measures for projects of this nature. Therefore, much of the work undertaken was exploratory, which the reader should bear in mind, for the remainder of the article.

\section{Implementation}

The duration of the field trip was four days with projects being carried out for three days and the fourth day being used for each group to discuss and evaluate their project.For a detailed timetable of the trip, see Appendix.

\section{Language Stimulation Project}

The aim of this project was for Wits staff and students and members of the Tintswalo rehabilitation team to provide information about language development, stimulation and play to childminders belonging to a support group in Gazankulu.

Background information. The Tintswalo rehabilitation team coordinates a support programme for childminders at local creches and has organised an association called Hlangavani Creche Teachers Support Group whose aim is:

1) To provide support and training for childminders in the region, through the running of workshops by training associations such as the Montessori Society of Child Centered Education. Childminders are generally untrained and often work on a voluntary basis.

2) To assist with fundraising for creches in this region.

Reynolds (1989) has contended that in societies such as the one being described, adults tend not to play with their children as play is regarded as being undignified. In addition, it has been noted by members of the Tintswalo rehabilitation team that parents tend to perceive feeding and day-care rather than preschool education, to be the primary functions of creche. Members of the Tintswalo rehabilitation team, based on their professional knowledge, considered that the time the children spent at creche could be maximally utilised by engaging in such activities as play. Childminders had also agreed to this when receiving information regarding the importance of play, at regular interactions between them and members of the Tintswalo rehabilitation team. Thus, the need for a programme, in the form of a workshop, dealing with language stimulation and play had been identified by childminders and the Tintswalo rehabilitation team.

The childminders were notified about the proposed workshop by one of the OTs from the Tintswalo rehabilitation team, who organised accommodation for them. Eight childminders attended the workshop which was facilitated by six Wits students, a staff member and a community worker in speech and hearing. The aim of the facilitators was to increase the childminders' motivation to learn and act on this learning, as suggested by Brookfield (1986). In order to obtain maximal benefit and participation, members were divided into two equal groups from the second day of the programme. The same format was adopted for both groups.

Location. The workshops were held at:

1. Pfukani Creche which has an enrolment of 30 children and primarily caters for the children of Tintswalo hospital staff. A number of disabled children also attend this creche.

2. Hluvukani Creche which is a community,creche catering for 250 children, mostly refugees. This creche is assisted by Operation Hunger.

The programme was conducted in English at Pfukani Creche as all participants could communicate in English. At Hluvukani Creche, however, as two caregivers did not understand English, all input was translated by a member of the group who was fluent in both English and Tsonga. The com- 
munity worker in speech and hearing, although fluent in both languages, was not used as the translator, as her role in this group was that of facilitator.

The programme. According to Twelvetrees (1986, p. 21) certain basic methods are followed in community work, that is, "to study the situation, establish rapport and gather information" and in accordance with this, the functioning of the two creches and the interaction of childminders with the children were observed by the facilitators on the first day. This observation confirmed the need, previously identified, to provide childminders with information about language stimula tion. It was apparent that childminders were not allowing children to play, and that they were providing much information at inappropriately high levels: eg. teaching three to six year old Shangaan speakers approximately 15 new English words in the space of 10 minutes, by having them imitate the childminder. This was particularly true at Pfukani Creche.

Based on the information obtained, the facilitators prepared an educational programme consisting of talks and activities such as role play and poster presentations. Information was to be provided on language and its development, language stimulation, the importance of play and how to incorporate this into a creche programme.

This programme was implemented on the second and third day of the field trip with techniques such as role-playing, modelling and problem solving exercises being used to demonstrate principles and methods of the programme, rather than lecturing to childminders on the specific topics. The example noted at the observation, of the childminders attempting to teach English vocabulary by imitation, was used to demonstrate the difficulty of learning a language in this way, by the facilitators using the same ineffective methods of teaching a foreign language, Hebrew, to the childminders. An example of one of the subjects addressed in the workshop was effective story telling. This was demonstrated through role-play followed by a discussion with the facilitators and childminders on the principles of story telling. Childminders were then asked to role-play telling a story to the workshop. Finally, the childminders were given the opportunity of telling the story to children in the creches. Other similar role-plays and discussions were held over the two days to demonstrate other principles of language stimulation and play such as teaching body parts and singing. Posters were also used to explain the sequence of language development

\section{Evaluation}

Evaluation was carried out on an ongoing basis in accordance with the evaluation procedures, previously described by Cooper and Heenan (1980). In the-ongoing evaluation it was noted by the facilitators that the childminders participated enthusiastically in all activities and had acquired new and more effective skills in stimulating language development, in such activities as teaching vocabulary or songs. When teaching vocabulary childminders attempted to introduce only one or two new words into an activity. They would explain the word, for example, a particular object, by showing it to the children, describing it, enumerating its uses and allowing the children to play with it. In addition, the childminders displayed an ability to generate and expand on what they had been taught, for example by the incorporation of songs that the children knew, into a story. This resulted in the exposure of the children to more varied activities and input.

In the formal evaluation session held at the end of the third day, the childminders described the workshop positively and said that it had benefitted them. Examples provided of what they had learned were that they had not realised that children learn through play or that language learning is a gradual procedure. The success of the project, which was manifest both in terms of the increase in skills and the positive evaluation of participants can be seen as consistent with the principles of community work, that is language stimulation had been identified as a need, and therefore the childminders were motivated to carry out the programme as it served their needs and their potential for becoming self-sufficient, as advanced by Segal (1982).

The students also evaluated the workshop positively. The students at Hluvakani Creche found that the translation of the proceedings from English to Tsonga slowed down the process of giving information. However, they reported that this was extremely valuable in terms of exposing them to the inherent problem of not always speaking the same language as the client, so common in South Africa.

The community worker in speech and hearing commented on the positive changes she had seen taking place in the childminders interaction with their pupils. Her feedback was of particular value as she had experienced the childminders' previous lack of knowledge regarding language stimulation and play, while during the workshop she was able to view a constructive change in this. She expressed concern that these skills should be maintained and therefore implemented long term evaluation of this project by involving the Tintswalo rehabilitation team and the Hlangvani Creche Teachers Support Group.

\section{The Stroke Rehabilitation Project}

The aim of the project was to assist community rehabilitation workers in the practical aspects of identifying and assessing aphasia and planning suitable intervention procedures. Formal standardised aphasia tests for this population are not available, therefore a further aim was to develop basic identification and assessment procedures, suitable for use by the community rehabilitation workers.

Participants. Pairs, consisting of a Wits student and a community rehabilitation worker visited individual clients in the community rehabilitation workers' villages. A Wits staff member and a Tintswalo rehabilitation team member provided transport for the pairs and consulted with each pair when necessary to assist in evaluation.

The Programme. At the planning workshop, the following timetable was proposed. On the first day stroke patients who had previously been referred to members of the Tintswalo rehabilitation team or community rehabilitation workers, were to be observed in their homes. On the basis of these observations an aphasia evaluation and home therapy programme was to be devised, on the second day. The assessment was to be carried out with patients and its effectiveness assessed on the third day, and finally, on the fourth day, the home therapy programme was to be initiated and its success evaluated. Due to the considerable distances between villages however it was not practical to keep to this proposed timetable. This difficulty had not been foreseen initially. In addition, the implementation of the therapy programme on day four could not be carried out as many of the previously identified stroke patients did not present with aphasia, or were too frail and ill to receive therapy.

The programme for day one was implemented as planned. The observations of the stroke patients in their homes revealed that many of the patients were not aphasic. It was also realised that it took considerably longer than had been anticipated to transport pairs to their locations, in some instances up to two hours per pair. One of the reasons was that no maps or street names are available for the different villages and time was 
spent in asking directions from local residents.

On day two an aphasia assessment was devised for those stroke patients who appeared to present with aphasia. Broad areas were to be examined, for example, how to test receptive and expressive language, using objects and stimuli available in the patients' homes. This was successfully implemented on the third day. Also on this day, where appropriate, suggestions were made to families on how to communicate more effectively with their aphasic family member. At the request of the community rehabilitation workers the remainder of the day was used to assist them with other patients they had identified with communication problems such as mentally retarded or dysarthric children.

\section{Implications}

It was invaluable for Wits students to see patients in their home environments as this helped them to understand the overwhelming physical difficulties handicapped patients in rural areas have to contend with, eg. the uneven and eroded terrain that patients have to negotiate when going to the toilet. In addition, they were able to observe the close involvement of the extended family and neighbours in caring for the patient. This highlighted the need for the community rehabilitation worker to provide the family and community with education about stroke and management of the communication problems of the patient. It was particularly valuable for Wits staff and students, as members of a training institution, to experience the importance of community rehabilitation workers. This was evidenced in terms of their ability to relate to the patient and the family. It was clear that the shared community origins were most valuable in that the community rehabilitation workers understood the language, local customs and the needs of their community, which endorses Segal's observations (Segal, 1982). Furthermore, the presence of community rehabilitation workers in the villages, has made integrated assess ment and management programmes across disciplines, available in the homes of patients otherwise deprived of access to rehabilitation, which is available only in places far from their homes. As mentioned in an earlier section, community rehabilitation workers receive training in basic assessment and treatment principles of physiotherapy, occupational therapy and speech therapy. The benefit of this broad training gives them an integrated perspective of aphasia in relation to the patient's other disabilities, and helps them to treat patients holistically. This is a perspective which is often difficult for members of different paramedical professions to appreciate.

This project was successful too, in that the Wits students imparted specialist skills to the community rehabilitation workers to allow them to provide services to their own communities. According to Wagstaff (1984, p. 11) "Primary health care advocates ... team work and the responsible delegation of tasks for which necessary training has been given". From the experience of teaching students it is clear that there is a common misconception that community work must of necessity be carried out within groups. This project helped students to realise that community work can becarried out on a one to one basis. Students also learned about the need to be flexible when undertaking community work, as they observed how programmes had to be modified due to circumstances that could not be predicted, for example, the small number of patients who had aphasia, necessitated a change to the programme.

The assessment procedure was successful in identifying the presence or absence of aphasia. However, as few of the patients exhibited aphasia, it was not possible to demonstrate to the community rehabilitation workers the full evaluation of aphasic symptoms, such as perseveration or word finding dif- ficulties. Furthermore, due to the fact that there were so few aphasics, and that these were mostly elderly and many years post stroke, intervention procedures could not be demonstrated.

\section{Hearing Screening and Education Project}

Background information. This project took place in the village of Croquet Lawn following an incidence study undertaken by the Tintswalo rehabilitation team in 1990 , in which numerous patients with hearing loss were identified. In addition two deaf members belong to a self-help group that undertakes sewing and agriculture, with the purpose of obtaining an income which has been established in this area. It should be noted that self-help is a strategy that most typifies community work and aims to assist people in learning how to deal with their problems according to Mitchell (1987).

Aims. The aims for this project included hearing screening of children in the village pre-primary and primary school and diagnostic testing of pupils with known hearing losses in the high school. In addition educational talks providing information to teachers on such topics as hearing loss, basic ear hygiene and management of the hearing impaired child in the classroom were held. A final aim of this project was a talk to members of the self-help group to discuss deafness, causes of hearing loss and communication with the hearing impaired. This was conducted in oral and sign language.

Participants. A staff member and four students from Wits; a community worker in speech and hearing; and a community rehabilitation worker from Croquet Lawn were to administer this project.

The programme. Hearing screening of the pre-primary school took place on the first day of the project while the primary school was screened on the second day. Otoscopic examinations preceded the screening. As there was no electricity, a Liverpool screening audiometer and Peters audiometers were used. Screening levels were $50 \mathrm{~dB}$ at 500 and $1000 \mathrm{~Hz}$ and $30 \mathrm{~dB}$ at 2000 and $4000 \mathrm{~Hz}$ on the Liverpool audiometer due to high levels of ambient noise and $35 \mathrm{~dB}$ at 500 , 1000,2000 and $4000 \mathrm{~Hz}$ on the Peters audiometer. In addition on the second day, diagnostic audiometry was administered to pupils at the high school who had previously been identified as having hearing problems. Thorough pure tone testing as suggested by Green (1985) was attempted but was not possible due to the fact that portable audiometers were used and no sound proof booths were available. Educational talks were delivered to teachers and members of the self-help group on the third day of the project, on the topics mentioned above. Both talks incorporated a discussion on the role of the community rehabilitation workers as regards identification, monitoring and referral of patients with hearing problems in the community.

Results. All the aims of this project were achieved. Otoscopic examinations revealed a high incidence of impacted wax. Referrals for removal of this were made to the local clinic or to the community worker in speech and hearing, who has a great deal of experience with wax removal. Children with'suspected ear infections were referred to the local clinic for treatment and children who failed the hearing screening, where there was no evidence of impacted wax or ear' infection, were referred to Tintswalo Hospital for further diagnostic testing.

Evaluation. This project was successful in that the following was achieved:

Hearing screening was successful in identifying children who had ear problems and needed treatment or referral. A positive outcome was that the students learned to apply their screening skills in a rural community and they reported be- 
coming more proficient in otoscopic examination. This project was also successful in emphasising the importance of the community rehabilitation worker and Tintswalo rehabilitation team in providing follow up for identified hearing problems

The importance of being appropriately prepared and of identifying community resources prior to embarking on such a project, was highlighted by participants in this project. For example, it was important to know before the field trip that there was no electricity in the pre-primary and primary schools, and that therefore it would be necessary to use batteryoperated audiometers. In addition, participants learned how to adapt basic procedures for the situation, for example, diagnostic testing with a portable audiometer.

\section{SUMMARY AND CONCLUSIONS}

When evaluating the results of the field trip it is important to remember that it lasted four days. Within that time, change was seen, but it is not yet clear whether there can be any long term effects in such a short time. Results and conclusions should thus be seen in the light of this. The specific objectives of the three projects were achieved with the exception of implementing aphasia assessment and intervention. This was due to factors that could not have been anticipated such as the fact that not all stroke patients had aphasia. During the exposure to community work, participants learned the importance of being flexible and of being able to adapt to existing conditions.

The successful working relationships between speech and hearing therapists, community workers in speech and hearing, and community rehabilitation workers, as well as occupational therapists, was proved to be particularly appropriate for the context of the field trip. In addition, results of the field trip indicated that a coordinated team such as the one used, provided an integrated and effective community service. A large part of the success of this service can be attributed to the fact that follow up of referrals was made possible by the existing infrastructure of the 'T'intswalo rehabilitation teams and community rehabilitation workers. It would have been irresponsible to undertake community work projects without providing the necessary follow up services.

As regards the aims of the various participants of the field trip, the Tintswalo rehabilitation team considered the field trip successful as the projects were planned according to their identified needs and provided the personpower to undertake them. The community benefitted in that they received necessary language and hearing services. The Wits students and staff, on the other hand gained an insight and increased proficiency for community work from this field trip. Much of the value was derived from the reality of the aims and the work done. This trip did not merely provide an opportunity for 'rural tourism'. Finally, this project achieved, to a certain extent, an objective of community work which is to enable the communities to acquire the skills and confidence to tackle problems which are necessary to ensure that concrete changes are brought about in the community (Twelvetrees, !1986).

\section{ACKNOWLEDGEMENTS}

The writers gratefully acknowledge the assistance of Ms. M. Schneider for participating in this project under laborious circumstances. The assistance of the students is also warmly appreciated.

\section{REFERENCES}

Adler, S. (1979). Poverty children and their language: Implications for teaching and treating. New York: Grune and Stratton.

Aron, M. A. (1984). Introduction. Proceedings of conference on com. munity work in speech and hearing theraph. Johannesburg: University of the Witwatersrand.

Brookfield, S. D. (1986). Understanding and facilitating adult learning. Milton Keynes: Oxford University Press.

Butler, J. (1989). Child health surveillance in primary care: A critical review. London: Her Majesty's Stationery Office.

The Calouste Gullbenkian Foundation. (1973). Current issues in com munity work. A study by the community work group. I.ondon: Routledge \& Kegan Paul

Cooper, S., \& Hccnan, C. (1980). Preparing, designing and leading workshops: A humanistic approach. Boston: CBI Publishing.

de Vries, G. (1984). Community work in health. Procepdings of con ference on community work in speech and hearing therapy. Johannesburg: University of the Witwatersrand.

Drew, M. E. (1982). Editorial. South African Speech and Hearing Asso ciation Newsletter, 250, 1-6.

Gerber, S. E. (1990). Prevention: The etiology of communicative disorders in children. Englewood Cliffs, New Jersey: Prenticc Hall

Green, D. S. (1985). Purc tone air-conduction testing. In J. Katz (Ed.), Handbook of rlinical audiology (3rd ed.). (pp. 98-109).Baltimore: Williams and Wilkins

Kibel, M. A. \& Wagstaff, I. A. (1991). Child health for all: A munual for Sowthern Africa. Cape Town: Oxford University Press.

Mitchell, W. (1987). Social work with communities. In B. W. McKen drick (Ed.), Introduction to Social Work in South Africa. Pinetown: Owen Burgess.

Penn, C. (1978). Speech pathology and audiology in South Africa Past, present and future perspectives. In L.W. Lanham \& K.P. Prin sloo (Eds.), Language and communication studies in South Africa: Current issues and directions in research and incuiry. Cape Town Oxford University Press.

Reynolds, P. (1989). Childhood in Crossroads: Cognition and soriety in South Africa. Claremont: David Phillip.

Segal, D. (1982). Community-based therapy: Some preliminary suggestions. South African Spech and Hearing Asworiation Newslettr. $251,15-18$.

Twelvetrees, A. (1986). Communitu work. London: Macmillan Education.

Unit for the Development of Rehabilitation Strategies. (1992). Repor on the training of community rehabilitation worker students. Unpu blished document. 'Jintswalo Hospital, Gazankulu.

Wagstaff, L. A. (1984). The need to work in the community. Proceedings of conference on community work in speech and hearing therapy. Johannesburg: University of the Witwatersrand.

Walt, G. \& Vaughan, P. (1981). An introduction to the primary health care approach in developing countrics. A review with selected annotated references. Ross Institute of Tropical Husgicnt Publiration No 13. London.

Wits Rural Facility. (1991). Introduction to the Mhala resion of the Eatstern Transvaal. Unpublished document. Wits Rural Facility.

Address correspondence to Ms. M. Bortz, Department of Speech Pathology and Audiology. University of the Witwatersand, Private Bag 3. WITS, 2050, South Africa. 
APPENDIX 3

PROPOSED PROGRAMME FOR FIELD TRIP TO GAZANKULU, 1 - 5 SEPTEMBER,1992.

\begin{tabular}{|c|c|c|c|}
\hline PROJECTS & $\begin{array}{c}1 . \\
\text { LANGUAGE } \\
\text { STIMULATION }\end{array}$ & $\begin{array}{c}2 . \\
\text { STROKE } \\
\text { REHABILIATION }\end{array}$ & $\begin{array}{c}3 . \\
\text { HEARING SCREENING AND } \\
\text { EDUCATION }\end{array}$ \\
\hline DAY 1 & Observe at Creches & Observe at stroke patients' homes & $\begin{array}{l}\text { Screen hearing at pre-primary } \\
\text { school }\end{array}$ \\
\hline DAY 2 & Implement programme & $\begin{array}{l}\text { Devise aphasia evaluation and } \\
\text { home therapy programme }\end{array}$ & $\begin{array}{l}\text { Screen hearing at primary } \\
\text { school. } \\
\text { Diagnostic audiometry at high } \\
\text { school. }\end{array}$ \\
\hline DAY 3 & $\begin{array}{l}\text { Implement programme and } \\
\text { evaluate }\end{array}$ & $\begin{array}{l}\text { Implement assessment, evaluate } \\
\text { and counsel families }\end{array}$ & $\begin{array}{l}\text { Educational talks to teachers and } \\
\text { self-help group. }\end{array}$ \\
\hline DAY 4 & & $\begin{array}{l}\text { Institute home therapy } \\
\text { programme }\end{array}$ & \\
\hline
\end{tabular}

EVALUATION OF FIELD 'I'RIP BY PR'IICIPANTS 